\title{
Research and Teaching Practice on Experiment Course of STM32-Embedded Microcontroller
}

\author{
Jialin Song ${ }^{1,2}$ \\ ${ }^{1}$ Institute of Electrical Engineering \\ Yanshan University \\ ${ }^{2}$ Measurement Technology and Instrumentation Key Lab of \\ Hebei Province \\ Qinhuangdao, P.R.China
}

\author{
Hui Meng ${ }^{1,2 *}$ \\ ${ }^{1}$ Institute of Electrical Engineering \\ Yanshan University \\ ${ }^{2}$ Measurement Technology and Instrumentation Key Lab of \\ Hebei Province \\ Qinhuangdao, P.R.China
}

\begin{abstract}
The experiment course of STM32 embedded microcontroller is very comprehensive and practical. The traditional teaching method can no longer meet the requirements of the course, and it is not conducive to cultivating applicationoriented and innovative talents. According to the features of STM32 embedded microcontroller experiment course, the authors set up a comprehensive experimental equipment platform to effectively carry out basic experiments, design experiments and comprehensive experiments. In this paper, several improved teaching methods are put forward, including the effective use of multimedia and network, the introduction of project-based teaching, and the improvement of assessment methods. Practices show that these measures improve the initiative of students' learning and effectively improve the quality of teaching.
\end{abstract}

Keywords-curriculum reform; practice teaching; projectbased teaching; STM32-embedded microcontroller

\section{INTRODUCTION}

With the rapid development of social economy, the application products related to embed system are constantly being developed [1]. In these applications, the STM32 series products become the mainstream microcontroller products due to its high performance, low power consumption, low cost and many other advantages. STM32 series chips have been widely used in real-time control, handheld devices, motor drive and other fields [2]. There is a great demand for talents to master the application of STM32 embedded microcontroller. In order to keep up with the rapid development of technology, many colleges and universities in China transform the course of MCS-51 microcontroller which has been taught for nearly 30 years into the course of STM32 embedded microcontroller [3]. The embedded system has been listed as the core course in the CC2004 computer curriculum system developed by the IEEE Computer Association and ACM [4]. Practices in recent years have shown that STM32 embedded microcontroller course has a great role in promoting students to participate in various electronic design competitions and increasing their employment opportunities [5].

The STM32 embedded microcontroller course has a wide range of knowledge and practicality and pays more attention to engineering and application. If the traditional teaching method is still adopted and there are only a few experimental courses, the teaching effect will certainly not be ideal. According to the features and teaching goals of experiment course of STM32 embedded microcontroller, the authors reformed the traditional teaching method in experimental teaching. Better teaching results have been obtained by improving teaching methods.

\section{FEATURES OF STM32-EMBEDDED MicROCONTROLLER EXPERIMENT COURSE}

Many colleges and universities in China selected MCS-51 series microcontroller for teaching 20 years ago. Due to low integration degree and simple peripheral circuit, the 51 series microcontrollers are easy to understand. However, the 51 series microcontroller has low performance, low on-chip resources, low development efficiency, and the code is not easy to reuse. Therefore, more and more colleges and universities have turn to STM32 embedded microcontroller, which is rich in resources and high in development efficiency [6]. However, the STM32 embedded microcontroller is very comprehensive, and it is impossible for students to fully grasp all the functions of STM32 by the time of the class alone. Through the experiment courses, students can master the general development process of STM32, which will lay the foundation for further learning about embedded system technology. In view of these, the teaching goals of the experiment course of STM32 embedded microcontroller developed by Institute of Electrical Engineering of Yanshan University are as follows:

- Based on the basic concept of electronics and embedded microcontroller, students can select the corresponding theory and analysis method, master the microcontroller hardware structure principle and applications.

- The standard C language and embedded microcontroller software design method can be used to establish the software flow of the embedded system and compile the corresponding software program.

- Be able to select the type of microcontroller reasonably for engineering application problems and carry out the scheme design of basic system circuit, program and other application.

- Be able to master the test and evaluation methods of embedded microcontroller application system, and have 
the basic abilities of corresponding experimental scheme design, data collection, analysis and processing.

Through the study of this course, students are required to build an experimental platform of embedded system and master the software and hardware design methods. If students want to learn this course well, it is not enough to rely only on reading books. They must understand the relevant principles of embedded system technology thoroughly through a large number of experimental operations and specific application examples. Such high teaching goals also pose challenges to experimental teachers. How to make efficient use of the experimental platform, design experimental items reasonably, and improve the teaching methods to help students gradually master the development technology of the embedded system is the subject that the experimental teachers should study.

\section{FORMATION OF EXPERIMENTAL EQUIPMENT PLATFORM}

Many colleges and universities take laboratory boxes or embedded development boards provided by manufacturers as teaching equipment. Although these devices have powerful and complete on-board functions and abundant teaching resources, they expose some problems in experimental teaching. The first is the contradiction between rich teaching resources and limited teaching hours. The experiment course of STM32 embedded microcontroller taught by the authors only has 16 class hours. This limited time is not enough for students to master the development of STM32 embedded technology. Many functions of laboratory boxes provided by manufacturers can't be fully utilized in teaching process. For colleges and universities, this brings about the increase of equipment cost and the difficulty of students' use. Secondly, the teaching cases provided by development boards mainly focus on individual functions, and the connection between them is not obvious, which can't show the comprehensive processing ability of STM32 embedded microcontroller. In the teaching process of colleges and universities, facing the requirements of a large number of beginners' alternate use, development boards also exposed many maladaptive conditions.

In view of the above situation, the STM32 embedded microcontroller experimental course taught by the authors adopt the self-developed experiment board [7] and selfdeveloped experiment box as the equipment platform of the overall experiment course. With STM32F103ZCT6 as the core, the self-developed experiment board adopts modular building block structure, including LED, button, buzzer, serial port, $\mathrm{I}^{2} \mathrm{C}$ interface and other parts. It supports JTAG/JLINK debugging and meets needs of the basic experimental teaching of embedded system. The board was welded by the students themselves in the previous EDA course, and each student had one board to avoid damage caused by cross-use. The experiment board is easy to carry and can be used by students in their spare time. In experiment class, students mainly use self-developed experiment box. The self-developed experiment box is compatible with the self-developed experiment board, with richer functions and some protective designs, which is easy to maintain and manage. The components and function modules used in the experiment box are in compliance with the general standard. If it is damaged during the experiment, it is only necessary to replace the damaged module or component, which will not cost too much maintenance cost and time. The experiment can be guaranteed to proceed normally. If students do not finish the experiment on time when they encounter problems in the class experiment, they can use the selfdeveloped experiment board to continue their study in their spare time. This experimental platform can help students overcome the bad influence of putting more emphasis on theory than on practice and greatly improve their practical ability.

\section{EXPERIMENT CONTENT}

According to the teaching goals of experiment course, the authors designed three kinds of experiment items in the course of practical experimental teaching, namely, basic experiments, design experiments and comprehensive experiments.

\section{A. Basic Experiments}

The basic experiments include two experiments. One is STM32 project establishment and GPIO control LED flashing, and the other is external interruption experiment.

1) STM32 project establishment and GPIO control LED flashing: Students are required to complete the experiment in two class hours, which is very tight. Therefore, students are required to preview before class and set up STM32 project on their own computers according to the steps in the experimental instruction. In the experiment class, students add library functions, write source code, and create object files in the project that have been built.

2) External interruption experiment: Students are required to review the external interrupt of STM32 embedded microcontroller before the experiment. Through the experiment, they should master the programming method of the interrupt configuration and realize the control of LED light on and off with key.

\section{B. Design Experiments}

The design experiments include four experiments, which timers are timing at any time, USART serial communication, DMA reading on-chip flash, and ADC voltage acquisition.

1) Timer timing at any time: STM32 universal timer is used for accurate timing to control LED on and off. Students are required to preview STM32 universal timer before class. Through the experiment, they should master the working mode of the timer and the configuration of the timing constant, and write the program to realize the LED light to turn off in seconds.

2) USART serial communication: The communication between the serial port of computer and the USART of STM32 is realized. The computer sends characters to the serial port of STM32 through the keyboard. STM32 transmits the received characters back to the computer, and displays the results through the serial port debugging assistant on the computer. Students are required to preview the STM32 universal synchronous/asynchronous transceiver USART prior to the experiment. Through the experiment, they should 
Therefore, in the process of teaching, the authors make full use of multimedia and network to improve teaching efficiency and get satisfactory teaching effect.

At the beginning of the whole course, various embedded devices developed based on STM32 can be demonstrated by video, and the application products can also be given to the students for personal operation experience to guide the students to have a strong interest in learning. At the beginning of the course of basic experiments and design experiments, the video related to circuit interface and program design is played. The teacher prompts and analyzes the key content in the video playing process, so that students can make clear the experiment process and experiment objectives. During the defense of comprehensive experiments, each group of students plays the recorded project result video, which is helpful for the teacher to evaluate the project completion and promote the communication between students.

The STM32 embedded microcontroller experiment course require various forms of teaching materials, including video, software, documents and other forms of materials to meet different needs of students in the learning process. The Xue Xi Tong (XXT) network teaching tool is applied to the teaching of experimental course. The teacher distributes a variety of learning materials through XXT. Students can ask questions online and teachers can answer questions online. Students can exchange learning experience and share learning experience to improve learning efficiency.

\section{B. Introducing the project-based teaching method}

The project-based teaching method is a new teaching mode, which is based on theoretical knowledge, project-centered, student-oriented and teacher-centered [8]. This method decomposes the contents of the course into several small projects. In the teaching process, students are the main part and teachers are the auxiliary part, so as to train students' practical ability and ability to transform knowledge into skills.

In the STM32 embedded microcontroller experiment course, debugging is an essential part of teaching. For beginners, there will inevitably be a variety of mistakes in the process of the experiment, and they must be modified repeatedly to meet the requirements of the experiment. Students need a lot of practice time to explore and summarize more effective debugging methods. In the course of teaching, the authors pay attention to allowing students to carry out their own design and development so as to improve students' problem-solving ability. Teachers only give guidance, suggestions and evaluation in the process of students' design practice.

\section{Setting different teaching objectives according to students' aptitude}

For students with poor foundation and failing to complete the experiment in class, they should be urged to use the experiment board to complete the experiment after class and be checked in the next experiment class. For students who have the ability to learn more, some extended learning tasks are arranged in each class, so that students can learn the required knowledge by themselves through different learning tasks. Students can discuss with teachers about problems they

\section{A. Making full use of multimedia and network for teaching \\ STM32 embedded microcontroller experiment course is a course that integrates many kinds of technologies. The traditional teaching method can't achieve the teaching goal.}


software programming to hardware design. Only traditional teaching method can't achieve the teaching goal. According to the features of the STM32 embedded microcontroller experiment course, the authors set up the STM32 experimental equipment platform which combines the self-developed experiment board and the self-developed experiment box, so as to making full use of the students' time in and out of class. In the process of teaching, three kinds of experimental items are designed to guide students mastering embedded system knowledge in experimental practice, namely basic experiments, design experiments and comprehensive experiments. In the experiment course, the authors adopted a variety of teaching methods and improved the course assessment method. Through learning of this experiment course, students' development ability of embedded system has been cultivated and improved.

\section{ACKNOWLEDGMENT}

The authors are grateful to editors and reviewers of the paper for their helpful comments and suggestions to improve the quality of this paper.

\section{REFERENCES}

[1] S. Deniziak, R. Tomaszewski, "Co-synthesis of contention-free energyefficient NOC-based real time embedded systems,” J. Syst. Architect. Amsterdam, vol. 98, pp. 92-101, September 2019.

[2] T. Zhang, Y. Liao, "Attitude measure system based on extended Kalman filter for multi-rotors," Comput. Electron. Agr. Oxford, vol. 134, pp. 1926, March 2017.

[3] L. Chen, J. Deng, "Research and practice on experiment teaching of embedded system design based on STM32 in independent college,” Edu. T. Forum. Shijiazhuang, vol. 25, pp. 181-183, June 2017. (In Chinese)

[4] S. Hu, H. Cao, X. Wu, Z. Xi, Z. Tang, "Application of USMART debugging method in embedded system teaching," Info \& Comm. Wuhan, vol. 161, pp. 130-131, May 2016. (In Chinese)

[5] F. Bi, J. Chen, X. Cai, "Research on the teaching method of electronic competition training based on STM32 platform," Info \& Comm. Wuhan, vol. 168, pp. 274-275, December 2016. (In Chinese)

[6] C. Li, G. Xie, "Research on project-based embedded system practice teaching," Chn. Elec. Po. Edu. Beijing, vol. 306, pp. 183-184, November 2014. (In Chinese)

[7] H. Dang, "Embedded system experimental teaching research based on building modular structure,” Exp. Sci. Tech. Chengdu, vol. 14, pp. 158159, February 2016. (In Chinese)

[8] P. Wang, X. Su, "Research on teaching method of embedded system course based on project driven,” J. Edu. Tech. Wuhan, vol. 17, pp. 79-81, July 2018. (In Chinese) embedded microcontroller courses. The contents of STM32 embedded microcontroller course have a wide range, from 